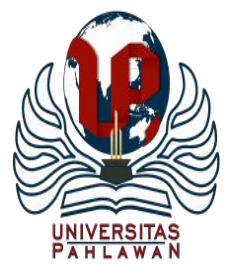

Edukatif : Jurnal Ilmu Pendidikan Volume 3 Nomor 5 Tahun 2021 Halm 2187 - 2193

EDUKATIF: JURNAL ILMU PENDIDIKAN

Research \& Learning in Education

https://edukatif.org/index.php/edukatif/index

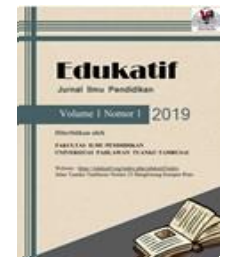

\title{
Pengaruh Pemberian Apersepsi Scene Setting terhadap Kesiapan Belajar Siswa pada Mata Pelajaran PPKN
}

\author{
Lusi Hidayanti $^{1 凶}$, Siti Awaliyah ${ }^{2}$, Nuruddin Hady $^{3}$ \\ Universitas Negeri Malang, Indonesia ${ }^{1,2,3}$

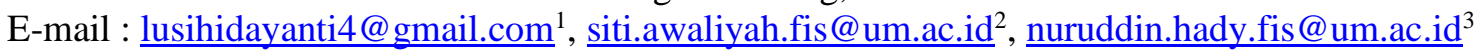

\begin{abstract}
Abstrak
Penelitian ini bertujuan untuk mengetahui pengaruh pemberian apersepsi scene setting terhadap kesiapan belajar siswa. Metode penelitian ini adalah metode kuantitatif. Pada penelitian ini, variabel independennya yaitu pemberian apersepsi scene setting dan variabel dependennya yaitu kesiapan belajar siswa. Teknik sampelnya dengan total sampling. Data yang dikumpulkan dengan menggunakan kuesioner. Populasinya yaitu kelas X SMA Kertanegara Malang yang berjumlah 30 orang. Uji asumsi klasik menggunakan uji validitas data, uji reliabilitas data, uji normalitas data, dan uji linieritas. Kemudian Data yang telah terkumpul dari dua kuesioner tersebut, dianalisis dengan menggunakan uji regresi linier sederhana. Hipotesis yang digunakan yaitu terdapat pengaruh pemberian apersepsi scene setting terhadap kesiapan belajar siswa. Kesimpulan dari penelitian ini adalah Pemberian apersepsi scene setting berpengaruh terhadap kesiapan belajar siswa pada pelajaran PPKn dengan nilai signifikansi $0,00(0,000<0,05)$. Besarnya kontribusi melalui nilai koefisien determinasi ( $\mathrm{R}$ square) sebesar 0,811 atau $81,1 \%$, yang mana variabel pemberian apersepsi scene setting memberikan sumbangan pengaruh sebesar $81,1 \%$.
\end{abstract}

Kata Kunci: apersepsi scene setting, kesiapan belajar, PPKn.

\begin{abstract}
This research was used to determine the effect of setting scene setting perceptions on the learning readiness of students.. This research method is a quantitative method. In this study, the independent variable is the provision of scene setting aperception and dependent variable is the student's learning readiness. Sample technique with total sampling. Data collected using questionnaires. The population is class X sma Kertanegara Malang which amounts to 30 people. Classic assumption tests use data validity tests, data reliability tests, data normality tests, and linearity tests. Then the data that has been collected from the two questionnaires, analyzed using a simple linear regression test. The hypothesis used is that there is an influence of the provision of scene setting aperceptions on students' learning readines. The conclusion of this study is that the provision of scene setting aperception affects students' learning readiness in PPKN subjects with a significance score of $0.00(0.000<0.05)$. The amount of contribution through the value of the coefficient of determination ( $R$ square) is 0.811 or $81.1 \%$, which variable of setting scene perception contributes an influence of $81.1 \%$.
\end{abstract}

Keywords: Apperception, Readiness Learning, PPKn.

Copyright (c) 2021 Lusi Hidayanti, Siti Awaliyah , Nuruddin Hadi

$\triangle$ Corresponding author

Email : lusihidayanti4@gmail.com

DOI : https://doi.org/10.31004/edukatif.v3i5.783

ISSN 2656-8063 (Media Cetak)

ISSN 2656-8071 (Media Online) 
2188 Pengaruh Pemberian Apersepsi Scene Setting terhadap Kesiapan Belajar Siswa pada Mata Pelajaran PPKN - Lusi Hidayanti, Siti Awaliyah , Nuruddin Hadi

DOI: https://doi.org/10.31004/edukatif.v3i5.783

\section{PENDAHULUAN}

Pendidikan mempunyai manfaat penting bagi hidup manusia. Manusia tidak bisa lepas dari pendidikan, hal ini karena dengan adanya pendidikan manusia bisa mengikuti perkembangan zaman. Pendidikan juga bisa dijadikan sebagai sarana untuk memajukan dan meningkatkan kualitas sumber daya manusia. Kemudian aktivitas yang paling penting dalam pendidikan yaitu ketercapaian tujuan pendidikan melalui perubahan tingkah laku siswa. Proses pembelajaran yakni kegiatan penyampaian materi kepada siswa oleh guru (Kurniawan, 2015). Pada proses pembelajaran, akan terlaksana sesuai target apabila terdapat komponen penunjang. Komponen itu seperti media pembelajaran yakni sebagai sumber belajar. Kemudian materi dan pembelajaran, serta adanya rencana pembelajaran yang sistematis (Nugroho, 2017).

Salah satu faktor keberhasilan proses belajar yakni ketika siswa berinteraksi dengan pengalaman belajarnya. Menurut teori, kesiapan belajar siswa bisa mempengaruhi karakteristik kognitifnya. Kesiapan atau readiness merupakan kemauan dalam memberikan respon atau menunjukkan reaksi. Salah satu faktor keberhasilan proses belajar yakni ketika siswa berinteraksi dengan pengalaman belajarnya (Indriastuti, 2017). Kemudian (Slameto, 2013), mendefinisikan kesiapan adalah kesediaan atau kesiapan seseorang memberikan jawaban atau respon tertentu dan dalam situasi tertentu. Kondisi siswa yang bagus yakni siswa semangat dalam memberikan respon kepada guru dan fokus pada pelajaran yang diajarkan guru. Hal tersebut akan menjadikan siswa cepat tanggap dan juga mudah untuk menerima materi pelajaran. Namun, ada permasalahan yang menghambat keberhasilan proses belajar yaitu kurangnya kesiapan peserta didik dan siswa masih belum maksimal dalam menangkap dan memahami materi yang sudah disampaikan oleh guru (Sinta, 2017).

Berdasarkan pengamatan peneliti, kondisi tersebut sama dialami dengan siswa kelas X SMA Kertanegara. Siswa merasa loyo dan tidak bersemangat saat mengikuti pelajaran PPKn sehingga siswa tidak fokus dalam belajar dan merespon terhadap pelajaran yang disampaian oleh guru. Penyebabnya timbul karena siswa sudah merasa bosan dan lelah terhadap proses pembelajaran mereka yang sudah dilakukan sebelumnya. Upaya yang dapat dilakukan oleh guru yaitu dengan memberikan apersepsi di awal pembelajaran. Apersepsi ini berguna untuk mendukung kesiapan belajar siswa dan membuat siswa agar mudah dalam memahami materi pembelajaran. Menurut (Chatib, 2016) bahwasanya satu jam awal pembelajaran merupakan waktu terpenting. Kemudian dalam Kamus Besar Bahasa Indonesia, yang dimaksud apersepsi merupakan proses mengamati secara sadar oleh diri sendiri dalam menerima sesuatu yang terjadi atau hal baru (Kaswara, 2017). Sedangkan (Chatib, 2016), berpendapat siswa akan tertarik dengan pembelajaran yang akan dilakukan dengan cara memberikan apersepsi sebagai stimulus awal. Apersepsi ini bertujuan untuk membentuk pemahaman. Prinsip apersepsi yakni untuk membuka pelajaran sehingga minat belajar siswa juga meningkat (Satria \& Kusumah, 2019). Semua mata pelajaran yang ada pasti memerlukan adanya apersepsi untuk mengawali proses pembelajaran, termasuk dalam pembelajaran mata pelajaran PPKn.

Berdasarkan penelitian yang dilakukan oleh (Prasetyaningtyas, 2019) adanya pengaruh positif apersepsi terhadap apersepsi siswa, juga penelitian oleh (Al-Muwattho et al., 2018) adanya pengaruh positif apersepsi terhadap kesiapan belajar siswa. Kemudian penelitian yang dilakukan oleh (Gunadi, 2019) yaitu menggunakan apersepsi warmer dan (Nugroho, 2017) menggunakan apersepsi fun story. Dari berbagai macam penelitian yang telah dilakukan, peneliti mencoba menggunakan apersepsi yang lain yaitu apersepsi scene setting. Konsep awalnya dibangun terlebih dahulu menggunakan Scene setting, hal tersebut karena yang paling dekat dengan strategi pembelajaran (Sunita \& Nardus, 2018). Scene setting ini berfungsi sebagai pembangkit minat siswa dalam mengikuti pembelajaran, kemudian untuk membangun konsep pembelajaran yang akan diberikan (Chatib, 2016). Perbedaan dari penelitian sebelumnya yakni terletak pada jenis apersepsi yang dilakukan dan mata pelajaran yang berbeda. Penelitian ini menggunakan apersepsi scene setting dan dilakukan pada mata pelajaran PPKn. Kemudian juga kondisi siswa di setiap sekolah berbeda dan cara menerima respon yang diberikan oleh guru juga akan berbeda. 
Pada mata pelajaran PPKn, mempunyai misi sebagai pendidikan nilai dan moral Pancasila. Kemudian sebagai upaya membentuk peserta didik menjadi manusia yang memiliki rasa kebangsaan dan cinta tanah air yang dijiwai oleh nilai-nilai Pancasila, UUD NRI Tahun 1945, semangat bhinneka tunggal ika, dan komitmen NKRI. Selain itu, bertujuan untuk mengembangkan kualitas warga negara secara dalam aspek kehidupan, agar peserta didik mampu berpikir rasional, berpartisipasi aktif, berkomitmen dan proaktif dalam berinteraksi, secara positif dan demokratis. Berdasarkan pengamatan peneliti, selama mata pelajaran PPKn dirasakan oleh siswa sebagai pelajaran yang membosankan, hanya penjelasan dan materi dari guru. Kemudian siswa sering terlambat masuk awal pembelajaran dan kurang bersemangat untuk memulai pelajaran. Dari alasan tersebut, peneliti ingin merubah citra mata pelajaran PPKn menjadi menyenangkan dan seru untuk siswa. Oleh sebab itu, peneliti menggunakan apersepsi scene setting agar siswa merasa senang dan tertarik untuk belajar PPKn. Menurut (Djamarah, 2002) faktor-faktor kesiapan belajar meliputi: (1) Kesiapan fisik, misalnya tubuh tidak sakit (jauh dari gangguan lesu, mengantuk, dan sebagainya). (2) Kesiapan psikis, misalnya ada hasrat untuk belajar, dapat berkonsentrasi, dan ada motivasi intrinsik. (3) Kesiapan materiil, misalnya ada bahan yang dipelajari atau dikerjakan berupa buku bacaan, catatan dll. Dari teori tersebut, untuk meningkatkan kesiapan belajar siswa diperlukan strategi guru yakni dengan menggunakan apersepsi agar siswa siap untuk menerima pelajaran.

Dari uraian di atas, penelitian ini dilakukan untuk membuktikan pengaruh pemberian apersepsi scene setting terhadap kesiapan belajar siswa. Penelitian ini sangat berguna untuk kelancaran proses pembelajaran yakni membuat siswa untuk siap menerima pembelajaran dari guru. Hal tersebut perlu dilakukan karena melihat kondisi kesiapan belajar siswa kelas X di SMA Kertanegara masih kurang saat pembelajaran mata pelajaran PPKn berlangsung. Dengan adanya permasalahan di atas, maka peneliti ingin membuktikan pengaruh pemberian apersepsi scene setting terhadap kesiapan belajar siswa.

\section{METODE PENELITIAN}

Metode penelitian ini yaitu metode penelitian kuantitatif. Metode ini digunakan untuk menguji teoriteori tertentu dengan cara meneliti hubungan antara variabel (Creswell, 2017). Pada penelitian ini menggunaka dua jenis variabel, yaitu variabel independen (X) dan variabel dependen (Y). Pada penelitian ini, variabel independennya adalah pemberian apersepsi scene setting $(\mathrm{X})$ dan variabel dependennya adalah kesiapan belajar siswa (Y). Pada penelitian ini, populasinya yaitu kelas X SMA Kertanegara Malang tahun ajaran 2020/2021. Teknik sampel yang digunakan adalah total sampling yang menjadikan seluruh anggota populasi menjadi anggota sampel penelitian yakni berjumlah 30 siswa. Data penelitian dikumpulkan dengan menggunakan dua kuesioner yaitu kuesioner untuk mengukur pemberian apersepsi scene setting dan kuesioner untuk mengukur kesiapan belajar siswa. Uji asumsi klasik menggunakan uji validitas data, uji reliabilitas data, uji normalitas data, dan uji linieritas. Kemudian data yang telah terkumpul dari dua kuesioner tersebut, dianalisis dengan menggunakan uji regresi linier sederhana. Analisis data dilakukan dengan menggunakan program SPSS 25.0 for windows. Hipotesis yang disusun oleh peneliti yaitu terdapat pengaruh pemberian apersepsi scene setting terhadap kesiapan belajar siswa.

\section{HASIL DAN PEMBAHASAN PENELITIAN}

Tahap awal dilakukan pada analisis penelitian ini adalah, melakukan uji Validitas Data. Validitas yakni alat yang digunakan untuk menentukan hasil tes belajar. Validitas digunakan untuk menguji kevalidan instrumen untuk menentukan hasil peneliti yang dikaji (Siyoto, 2015). Hasil uji validitas tabulasi kuisioner dengan metode Pearson Product Moment menunjukkan bahwa jawaban responden terhadap kuisioner yang diberikan valid dan reliabel. Dasar pengambilan uji validitas Pearson Product Moment dengan membanding 
nilai $r$ hitung dengan $r$ tabel. Jika nilai $r$ hitung lebih besar dari $r$ tabel, maka data tersebut valid. Jika nilai $r$ hitung kurang dari $r$ tabel, maka data tersebut tidak valid. Hasil perhitungan hasil uji validitas $r$ product moment person dalam taraf signifikansi 5\% dikarenakan terdapat sampel sebanyak 30 maka signifikansinya adalah 0,361. Dari item yang telah dilakukan penelitian ke 30 siswa diketahui 25 item valid dan tidak ada item yang tidak valid.

Setelah tahap validitas, yang dilakukan adalah melakukan uji Reliabilitas Data. Reliabilitas bisa dimaknai alat ukur untuk menunjukkan data itu dapat dipercaya dan diandalkan. Reliabilitas dilihat berdasarkan koefisien alpha cronbach. Suatu alat ukur dikatakan reliabel jika memiliki nilai alpha cronbach $\geq$ 0,700 (Siyoto, 2015). Uji reliabilitas bertujuan untuk melihat apakah kuisioner memiliki konsistensi jika pengukuran dilakukan dengan kuisioner tersebut dilakukan secara berulang (Gunadi, 2018). Uji reliabilitas yang dilakukan terhadap item pertanyaan diperoleh nilai koefisien sebesar 0,823 untuk variabel X dan 0,943 untuk variabel Y. Hasil ini menunjukkan bahwa nilai reliabilitas instrumen dari variabel X dan Y lebih besar dari 0,700. Maka dari hasil uji reliabilitas disimpulkan kedua variabel tersebut reliabel.

Kemudian tahap selanjutnya adalah uji normalitas data. Uji normalitas bertujuan agar data tersebut diketahui normal atau tidak distribusinya. Pada penelitian ini, Uji normalitas dengan metode One Sample Kolmogorov Smirnov dengan taraf signifikansi 0,05. Data berdistribusi normal apabila signifikansi lebih besar dari 0,05 (Priyatno, 2014). Uji normalitas ini dengan teknik one-sample kolmogrov-Smirnov Test dengan bantuan SPSS 25.0 for windows. Skor variabel yang di uji normalitas adalah apersepsi scene setting (X) dan kesiapan belajar (Y). Dengan ketentuan jika signifikansi kurang dari 0,05 data dinyatakan tidak terdistribusi dengan normal dan jika signifikansi lebih dari 0,05 data dinyatakan terdistribusi dengan normal.

\begin{tabular}{llr}
\hline \multicolumn{3}{c}{ Tabel 1. Hasil uji normalisasi data } \\
\hline \multicolumn{3}{c}{ One-Sample Kolmogorov-Smirnov Test } \\
\hline $\mathrm{N}$ & \multicolumn{2}{c}{$\begin{array}{c}\text { Unstandardized } \\
\text { Residual }\end{array}$} \\
\hline Normal Parameters ${ }^{\mathrm{a}, \mathrm{b}}$ & Mean & 30 \\
\cline { 2 - 3 } & Std. Deviation & 3,93632986 \\
\hline Most Extreme Differences & Absolute &, 121 \\
\cline { 2 - 3 } & Positive &, 121 \\
\cline { 2 - 3 } & Negative &,- 098 \\
\hline Test Statistic & &, 121 \\
\hline Asymp. Sig. (2-tailed) & &, $200^{\mathrm{c}, \mathrm{d}}$ \\
\hline
\end{tabular}

Tabel 1 menunjukkan nilai signifikasi 0,200. Dari hasil uji normalitas di atas, nilai signifikan 0,200 lebih dari 0,005, maka dapat disimpulkan bahwa nilai residual berdistribusi normal.

Kemudian tahap analisis regresi linear sederhana. Analisis regresi linear sederhana dimaksudkan untuk menguji pengaruh satu variabel bebas terhadap variabel terikat (Al-Muwattho et al., 2018). Pada penelitian ini terdapat variabel independen (X) dan dependen (Y). Variabel independennya yakni pemberian apersepsi scene setting variabel dependennya yakni kesiapan belajar siswa. Pada penelitian ini uji regresi linear sederhana adalah menguji pengaruh pemberian apersepsi scene setting terhadap kesiapan belajar siswa. Syarat analisis regresi linear sederhana yaitu 1) valid dan reliabel; 2) normal dan linear (Kurniawan, 2016). Dasar pengambilan keputusan yakni membandingkan nilai signifikansi dengan nilai probabilitas 0,05 yaitu, jika nilai signifikansi kurang dari 0,05 , artinya variabel $\mathrm{X}$ berpengaruh terhadap variabel $\mathrm{Y}$. Kemudian jika nilai signifikansi lebih besar dari 0,05, artinya variabel $\mathrm{X}$ tidak berpengaruh terhadap variabel. 
2191 Pengaruh Pemberian Apersepsi Scene Setting terhadap Kesiapan Belajar Siswa pada Mata Pelajaran PPKN - Lusi Hidayanti, Siti Awaliyah , Nuruddin Hadi

DOI: https://doi.org/10.31004/edukatif.v3i5.783

\begin{tabular}{|c|c|c|c|c|c|c|}
\hline \multicolumn{7}{|c|}{ Tabel 2. Hasil nilai signifikansi } \\
\hline \multirow[b]{2}{*}{ Model } & & Unstandardized & Coefficients & $\begin{array}{l}\text { Standardized } \\
\text { Coefficients }\end{array}$ & \multirow[b]{2}{*}{$\mathrm{t}$} & \multirow[b]{2}{*}{ Sig. } \\
\hline & & $\mathrm{B}$ & Std. Error & Beta & & \\
\hline \multirow[t]{2}{*}{1} & (Constant) & $-12,170$ & 6,129 & & $-1,986$ &, 057 \\
\hline & Apersepsi & 1,861 & , 170 & 901 & 10,967 & ,000 \\
\hline
\end{tabular}

a. Dependent Variable: Kesiapan Belajar

Dari tabel 2, diperoleh nilai sig 0,000 kurang dari 0,005, maka terdapat pengaruh yang signifikan pada pemberian apersepsi scene setting terhadap kesiapan belajar siswa.

\begin{tabular}{llrrrrr}
\hline \multicolumn{7}{c}{ Tabel 3. Hasil Uji Regresi } \\
\hline \multirow{2}{*}{ Model } & \multicolumn{1}{c}{$\begin{array}{c}\text { Sum of } \\
\text { Squares }\end{array}$} & df & Mean & Square & F & Sig. \\
\hline \multirow{2}{*}{1} & Regression & 1930,021 & 1 & 1930,021 & 120,265 &, $000^{\mathrm{b}}$ \\
\cline { 2 - 7 } & Residual & 449,346 & 28 & 16,048 & & \\
\cline { 2 - 6 } & Total & 2379,367 & 29 & & & \\
\hline
\end{tabular}

a. Dependent Variable: Kesiapan_belajar

b. Predictors: (Constant), Apersepsi

Dari tabel 3, diketahui bahwa nilai $\mathrm{F}$ hitung $=120,265$ dengan tingkat signifikansi sebesar 0,000 kurang dari 0,05, maka model regresi dapat dipakai untuk memprediksi variabel partisipasi atau dengan kata lain ada pengaruh variabel pemberian apersepsi scene setting $(\mathrm{X})$ terhadap variabel kesiapan belajar $(\mathrm{Y})$. Kesimpulan dari tabel 2 dan 3 yakni bahwasanya pemberian apersepsi scene setting mempengaruhi kesiapan belajar siswa secara signifikan, artinya semakin rendah pemberian apersepsi akan memiliki dampak pada rendahnya kesiapan belajar siswa. Kemudian tahap selanjutnya adalah mencari koefisien determinasi.

\begin{tabular}{lcccc}
\hline \multicolumn{5}{c}{ Tabel 4. Koefisien Determinasi } \\
\hline Model & R & R Square & $\begin{array}{c}\text { Adjusted R } \\
\text { Square }\end{array}$ & $\begin{array}{c}\text { Std. Error of } \\
\text { the Estimate }\end{array}$ \\
\hline 1 &, $901^{\text {a }}$ &, 811 &, 804 & 4,006 \\
\hline a. Predictors: (Constant), Apersepsi & & \\
\hline
\end{tabular}

Koefisien determinasi merupakan sumbangan pengaruh dari variabel independen $(\mathrm{X})$ terhadap variabel dependen (Y). Berdasarkan tabel tabel 4 dapat disimpulkan bahwa besarnya nilai korelasi/hubungan (R) yaitu sebesar 0,901. Berdasarkan data di atas, diperoleh koefisien determinasi (R Square) sebesar 0,811, yang berarti bahwa pengaruh variabel independen (Apersepsi scene setting) terhadap variabel dependen (Kesiapan belajar) adalah sebesar $81,1 \%$. Hal tersebut berarti bahwa variabel pemberian apersepsi scene setting memberikan sumbangan pengaruh sebesar $81,1 \%$ dan nilai sisanya 18,9\% dipengaruhi oleh variabel lain di luar variabel independen.

Dari hasil analisis diatas, bisa diambil kesimpulan bahwasanya dengan menggunakan apersepsi scene setting maka siswa dapat dengan semangat dan siap menerima pelajaran dari guru, siswa menjadi lebih fokus dalam belajar. Itu berbanding terbalik apabila tidak adanya pemberian apersepsi sebelum pembelajaran. Hal itu bisa menyebabkan siswa semakin tidak semangat untuk belajar, siswa yang pasif, dan kondisi kelas yang tidak kondusif karena siswa tidak mempunyai semangat belajar dan bosan. Kemudian juga bisa menjadi tidak fokus pada saat proses pembelajaran berlangsung. Hal tersebut dikarenakan kesiapan belajar siswa belum ada. 
Hasil penelitian lain juga dilakukan oleh (Gunadi, 2019) yaitu menggunakan apersepsi warmer berpengaruh terhadap hasil belajar siswa dan (Nugroho, 2017) menggunakan apersepsi fun story berpengaruh terhadap peningkatan motivasi belajar siswa. Sedangkan penelitian ini menggunakan apersepsi scene setting untuk mengukur pengaruh terhadap kesiapan belajar siswa. Namun dari penelitian ketiganya, dihasilkan kesimpulan yang sama yakni pemberian apersepsi berdampak positif bagi siswa. Pemberian apersepsi yang dilakukan sangat mempengaruhi kesiapan belajar siswa. Penelitian ini juga berdampak positif bagi siswa. Apersepsi dapat dibentuk melalui empat pilar, yaitu alfa zone, warmer, pree-teach dan scene setting. Apersepsi scene setting inilah merupakan strategi pembelajaran yang sering disebut pula sebagai hook atau pengait menuju mata pelajaran (Maksum, 2014). Menurut (Djamarah, 2002) faktor-faktor kesiapan belajar meliputi: (1) Kesiapan fisik, misalnya tubuh tidak sakit (jauh dari gangguan lesu, mengantuk, dan sebagainya); (2) Kesiapan psikis, misalnya ada hasrat untuk belajar, dapat berkonsentrasi, dan ada motivasi intrinsik.; (3) Kesiapan materil, misalnya ada bahan yang dipelajari atau dikerjakan berupa buku bacaan, catatan dll. Adanya pemberian apersepsi ini sangat berguna bagi kesiapan psikis siswa. Hal tersebut dibuktikan dengan siswa yang awalnya bosan dan tidak semangat mengikuti pelajaran, namun setelah adanya apersepsi scene setting siswa menjadi tertarik dan senang dengan pelajaran PPKn. Siswa sangat antusias saat berlangsungnya proses apersepsi scene setting. Apersepsi scene setting ini merupakan salah satu contoh stimulus yang sangat bermanfaat untuk menciptakan kondisi kelas dan suasana kelas menjadi lebih kondusif.

\section{KESIMPULAN}

Pemberian apersepsi scene setting berpengaruh terhadap kesiapan belajar siswa pada pelajaran PPKn kelas X SMA Kertanegara. Nilai signifikansi yang terhitung lebih kecil dari nilai signifikansi penelitian $(0,05)$. Hal tersebut dikarenakan kondisi kesiapan belajar siswa masih rendah. Maka dari itu, perlu adanya stimulus berupa apersepsi untuk meningkatkan kesiapan belajar siswa sehingga siswa belajar dengan semangat dan tetap fokus pada pembelajaran. Besarnya kontribusi pengaruh melalui nilai koefisien determinasi ( $\mathrm{R}$ square) sebesar 0,811 atau $81,1 \%$. yang mana variabel pemberian apersepsi scene setting memberikan sumbangan pengaruh $81,1 \%$ dan variabel lain menyumbang $18,9 \%$ sisanya.

\section{DAFTAR PUSTAKA}

Al-Muwattho, F. P., Aminuyati, A., \& Okianna, O. (2018). Pengaruh Pemberian Apersepsi Terhadap Kesiapan Belajar Siswa Pada Pelajaran Akuntansi Kelas XI SMA Islamiyah Pontianak. Jurnal Pendidikan Dan Pembelajaran Khatulistiwa, Https://Jurnal.Untan.Ac.Id/Index.Php/Jpdpb/Article/View/24076.Pdf.

Chatib, M. (2016). Gurunya Manusia. Bandung: Kaifa Pustaka Mizan.

Creswell, J. W. (2017). Research Design. Yogyakarta: Pustaka Pelajar

Djamarah, S. B. (2002). Rahasia Sukses Belajar. Jakarta: Rineka Cipta

Gunadi, F. (2019). Pengaruh Apersepsi Warmer Terhadap Hasil Belajar Matematika Siswa Materi Persamaan Kuadrat. Mathline: Jurnal Matematika Dan Pendidikan Matematika, 4(1), 33-40. Http://Mathline.Unwir.Ac.Id/Index.Php/Mathline/Article/View/102.Pdf. Diakses Pada 10 Juni 2021.

Indriastuti, A. (2017). Pengaruh Kesiapan Belajar Siswa Dan Keterampilan Mengajar Guru Terhadap Hasil Belajar. Jurnal Informasi Dan Komunikasi Administrasi Perkantoran, 2(1). Https://Jurnal.Fkip.Uns.Ac.Id/Index.Php/Jikap/Article/View/10513.Pdf. Diakses Pada 10 Juni 2021.

Kaswara, I. (2017). Pengaruh Pemberian Apersepsi Kemampuan Dasar Matematika Terhadap Kemampuan Siswa Menyelesaikan Soal Kesetimbangan Benda Tegar. Jurnal Pendidikan Dan Pembelajaran Khatulistiwa, 6(9). 
2193 Pengaruh Pemberian Apersepsi Scene Setting terhadap Kesiapan Belajar Siswa pada Mata Pelajaran PPKN - Lusi Hidayanti, Siti Awaliyah, Nuruddin Hadi

DOI: https://doi.org/10.31004/edukatif.v3i5.783

Kurniawan. (2015). Tri Pusat Pendidikan Sebagai Sarana Pendidikan Karakter Anak Sekolah Dasar. PEDAGOGIA: Jurnal Pendidikan, 4(1), 49. Http://Ojs.Umsida.Ac.Id/Index.Php/Pedagogia/Article/View/71

Kurniawan, $\quad$ R. (2016). Analisis Regresi. Prenada Https://Books.Google.Com/Books?Hl=Id\&Lr=\&Id=Kcy-

Dwaaqbaj\&Oi=Fnd\&Pg=PA43\&Dq=Analisis+Linear+Sederhana\&Ots=Creuwu6tu1\&Sig=WkgviY3joov8bvs5yoz9cdr8jw

Maksum, M. (2014). Menjadi Guru Idola. Klaten: Cable Book.

Nugroho, W. T. (2017). Pengaruh Apersepsi Fun Story Terhadap Peningkatan Motivasi Belajar Matematika (Penelitian Pada Siswa Kelas IV SD Negeri Tegalmiring Purworejo). Universitas Muhammadiyah Magelang. Http://Eprintslib.Ummgl.Ac.Id/49/

Prasetyaningtyas, F. D. (2019). Inovasi Model Quantum Learning Menggunakan Teori Apersepsi Berbasis Karakter Untuk Meningkatkan Kualitas Pembelajaran Matakuliah Pendidikan IPS SD. ELSE (Elementary School Education Journal): Jurnal Pendidikan Dan Pembelajaran Sekolah Dasar, 3(2), 16. Http://103.114.35.30/Index.Php/Pgsd/Article/View/2682

Priyatno, D. (2014). SPSS:Pengolahan Data Terpraktis. Yogyakarta: Andi Offset.

Satria, I., \& Kusumah, R. G. T. (2019). Analisis Keterkaitan Motivasi Dan Apersepsi Terhadap Hasil Belajar IPS. Indonesian Journal Of Social Science Education (IJSSE), 1(1), 114-123. Https://Ejournal.Iainbengkulu.Ac.Id/Index.Php/Ijsse/Article/View/2587

Sinta, V. (2017). Pengaruh Kesiapan Belajar Terhadap Hasil Belajar Mata Pelajaran Ekonomi Kelas X Di SMA Bina Jaya Palembang. Jurnal Ilmiah Pendidikan Dan Ekonomi, 1(1), 11-20. Http://Www.Journal.Stkipnurulhuda.Ac.Id/Index.Php/Utility/Article/View/59

Siyoto, S. Dan S. (2015). Dasar Metodologi Penelitian.

Slameto. (2013). Belajar Dan Faktor-Faktor Yang Mempengaruhinya. Jakarta:Rineka Cipta.

Sunita, N. W., \& Nardus, E. O. (2018). Pengaruh Penerapan Strategi Apersepsi Scene Setting Terhadap Pemahaman Konsep Matematika Dengan Mengontrol Motivasi Berprestasi. Emasains: Jurnal Edukasi Matematika Dan Sains, 7(1), 29-37. Https://13.251.174.250/Index.Php/Emasains/Article/View/80.Pdf. Diakses Pada 10 Juni 2021. 